\title{
Corneal biomechanical properties after laser- assisted in situ keratomileusis and photorefractive keratectomy
}

This article was published in the following Dove Press journal:

Clinical Ophthalmology

3 October 2017

Number of times this article has been viewed

\author{
Eileen S Hwang' \\ Brian C Stagg' \\ Russell Swan' \\ Carlton R Fenzl' \\ Molly McFadden ${ }^{2}$ \\ Valliammai Muthappan' \\ Luis Santiago-Caban' \\ Mark D Mifflin' \\ Majid Moshirfar ${ }^{1,3}$ \\ 'Department of Ophthalmology and \\ Visual Sciences, John A. Moran Eye \\ Center, ${ }^{2}$ Department of Internal \\ Medicine, University of Utah, Salt Lake \\ City, ${ }^{3}$ HDR Research Center, Hoopes \\ Vision, Draper, UT, USA
}

Correspondence: Majid Moshirfar HDR Research Center, Hoopes Vision, II 820 S State Street Suite \#200, Draper, UT 84020, USA

$\mathrm{Tel}+\mathrm{I} 8015680200$

Fax + I 8015630200

Email cornea2020@me.com
Background: The purpose of this study was to evaluate the effects of laser-assisted in situ keratomileusis (LASIK) and photorefractive keratectomy (PRK) on corneal biomechanical properties.

Methods: We used the ocular response analyzer to measure corneal hysteresis $(\mathrm{CH})$ and corneal resistance factor (CRF) before and after refractive surgery.

Results: In all, 230 eyes underwent LASIK and 115 eyes underwent PRK without mitomycin C (MMC). Both procedures decreased CH and CRF from baseline. When MMC was used after PRK in 20 eyes, it resulted in lower corneal biomechanical properties at 3 months when compared to the other procedures, but all three procedures had similar values at 12 months.

Conclusion: Significant but similar decreases in corneal biomechanical properties after LASIK, PRK without MMC, and PRK with MMC were noted.

Keywords: corneal biomechanics, photorefractive keratectomy, laser-assisted in situ keratomileusis, corneal hysteresis, corneal resistance factor, mitomycin $\mathrm{C}$

\section{Introduction}

Laser-assisted in situ keratomileusis (LASIK) and photorefractive keratectomy (PRK) are primary procedures for correction of refractive error. However, both procedures affect corneal biomechanical properties and may cause corneal ectasia, a postoperative complication.

The ocular response analyzer (ORA; Reichert Ophthalmic Instruments, Buffalo, NY, USA) measures corneal biomechanical properties in vivo. A puff of air indents the cornea, and an infrared beam measures the waveform during inward and outward deviations of the cornea. Two properties reported by the ORA are corneal hysteresis $(\mathrm{CH})$ and corneal resistance factor $(\mathrm{CRF}) .{ }^{1} \mathrm{CH}$ is the difference between the inward and outward applanation pressures and reflects the rigidity and elasticity of the cornea. CRF is calculated by multiplying the pressure at which the cornea returns to its original shape by an empirically derived constant and subtracting this value from the pressure required to indent the cornea. CRF correlates more strongly with central corneal thickness (CCT) than $\mathrm{CH}^{2}{ }^{2}$ Thin corneas are associated with lower $\mathrm{CH}$ and CRF values. ${ }^{3,4}$

Several studies have shown that refractive photoablation procedures decrease $\mathrm{CH}$ and $\mathrm{CRF},{ }^{5-9}$ but the stability of these biomechanical properties in the postoperative period has not been well established. No previous study has compared PRK with and without mitomycin $\mathrm{C}(\mathrm{MMC})$ to determine the effect of $\mathrm{MMC}$ on $\mathrm{CH}$ and $\mathrm{CRF}$. 
Here, we present a long-term, prospective study evaluating the effect of LASIK and PRK on corneal biomechanical properties over time and assess the factors that impact preoperative and postoperative $\mathrm{CH}$ and $\mathrm{CRF}$.

\section{Methods}

\section{Patients}

This prospective cohort study was conducted from November 2012 through February 2015. Patients underwent femtosecond LASIK or PRK for correction of myopia or myopic astigmatism. The vast majority of patients were given the choice between LASIK and PRK because the calculated residual stromal bed for LASIK was $>300 \mu \mathrm{m}$. However, some patients were only offered PRK because the calculated residual stromal bed for LASIK was $<300 \mu \mathrm{m}$. Patient choice determined whether LASIK or PRK was performed in most cases. All eyes were targeted for emmetropia. Eyes with prior eye surgeries, corneal disease, or topographic findings suggestive of ectatic disease were excluded.

The institutional review board from University of Utah, School of Medicine, approved the study protocol prior to November of 2012. The study adhered to the tenets of the Declaration of Helsinki. All patients provided written informed consent for surgery and study participation.

\section{Surgical procedures}

Femtosecond LASIK and PRK procedures were performed using standard techniques by four different surgeons (VM, LS-C, MDM, and MM). All excimer laser photoablation was performed using either the VISX Star S4 system (AMO, Santa Ana, CA, USA) or the WaveLight Allegretto EX200 and EX400 systems (Alcon Laboratories, Inc., Fort Worth, TX, USA). The Intralase femtosecond laser system (AMO) was used to create LASIK flaps with intended thickness of $110 \mu \mathrm{m}$ and $8.8 \mathrm{~mm}$ diameter. The following factors were used by the surgeon to determine whether or not to use MMC: $>6 \mathrm{D}$ of myopia and $>3 \mathrm{D}$ of cylinder. In these cases, a sponge soaked in $0.02 \%$ MMC was applied for 15 seconds followed by copious irrigation.

\section{Measurements}

Patients discontinued soft contact lens wear at least 2 weeks before baseline measurements. CCT was measured using the Pentacam (Oculus Inc., Arlington, WA, USA). Keratometry was measured using the ATLAS corneal topography system (Carl Zeiss Meditec AG, Jena, Germany), and values along the steep axis were included in the analysis. $\mathrm{CH}$ and $\mathrm{CRF}$ were measured using the ORA (Reichert Technologies, Depew, NY, USA). ORA measurements were performed at baseline and at 3 months, 6 months, and 12 months after surgery.

\section{Data analysis}

Baseline subject-level demographic variables were analyzed by the Kruskal-Wallis test for continuous variables and by the chi-square test for categorical variables. Baseline eye measurements were analyzed using a mixed-effect analysis of variance (ANOVA) to control for the correlation between eyes from the same subject. $p$-values for baseline variables were adjusted using the Tukey-Kramer method for multiple comparisons. Mixed-effects ANOVA with covariate adjustment was used to determine the mean $\mathrm{CRF}$ and $\mathrm{CH}$ at months 3, 6, and 12 after surgery. Mixed-effects ANOVA was used to control the correlation of eyes within each subject and simultaneously test for differences across eyes in the same subject. The effect of type of procedure on CRF and $\mathrm{CH}$ was tested after controlling for age, gender, baseline spherical equivalent, baseline keratometry value, ablation depth, and baseline CCT. An $\alpha=0.05$ was used for significance. Adjustment for multiple comparisons was not performed since all hypotheses tested were prespecified. Analyses were performed in SAS version 9.4 (SAS Institute Inc., Cary, NC, USA).

\section{Results}

\section{Baseline patient characteristics}

In all, 449 eyes (226 subjects) were enrolled in this prospective cohort study. A total of 365 eyes had complete baseline data and were included in the analysis. In all, 230 eyes underwent LASIK, 115 eyes underwent PRK without MMC and 20 eyes underwent PRK with MMC. A total of 194 eyes completed 12-month follow-up. The baseline characteristics of the groups differed in that LASIK patients had significantly thicker corneas and PRK with MMC patients had significantly greater refractive error. The groups were similar in age, gender, and keratometry values (Table 1). Baseline CRF and baseline $\mathrm{CH}$ were higher in the LASIK patients, as expected given the greater corneal thickness in this group.

\section{Changes in biomechanical properties after surgery}

Three months after surgery, CRF was significantly lower than baseline in eyes that underwent LASIK, PRK without $\mathrm{MMC}$, and PRK with MMC (Figure 1A). After controlling for baseline age, gender, spherical equivalent, keratometry value, ablation depth, and CCT, eyes that had PRK with MMC showed the greatest decrease in CRF from baseline to 3 months. Eyes that had PRK with MMC also demonstrated the greatest increase in CRF from 3 to 12 months. The pairwise 
Table I Baseline characteristics of study subjects

\begin{tabular}{|c|c|c|c|c|c|c|}
\hline \multirow{2}{*}{$\begin{array}{l}\text { Per subject baseline } \\
\text { characteristics }\end{array}$} & LASIK & $\begin{array}{l}\text { PRK without } \\
\text { MMC } \\
\end{array}$ & \multirow{2}{*}{$\begin{array}{l}\text { PRK with } \\
\text { MMC } \\
\text { Mean } \pm \text { SD }\end{array}$} & \multirow[t]{2}{*}{$p$-value } & & \\
\hline & Mean \pm SD & Mean \pm SD & & & & \\
\hline Age, years & $32.9 \pm 6.3$ & $30.8 \pm 5.3$ & $33.1 \pm 8.8$ & 0.164 & & \\
\hline Gender (\% males) & 53.4 & 57.9 & 66.7 & 0.622 & & \\
\hline \multirow[t]{2}{*}{$\begin{array}{l}\text { Per eye baseline } \\
\text { characteristics }\end{array}$} & LASIK & $\begin{array}{l}\text { PRK without } \\
\text { MMC } \\
\end{array}$ & $\begin{array}{l}\text { PRK with } \\
\text { MMC }\end{array}$ & $\begin{array}{l}\text { LASIK vs PRK } \\
\text { without MMC } \\
\end{array}$ & $\begin{array}{l}\text { LASIK vs PRK } \\
\text { with MMC } \\
\end{array}$ & $\begin{array}{l}\text { PRK without MMC } \\
\text { vs PRK with MMC } \\
\end{array}$ \\
\hline & Mean \pm SD & Mean \pm SD & Mean \pm SD & $p$-value & $p$-value & $p$-value \\
\hline CCT $(\mu \mathrm{m})$ & $549 \pm 28.1$ & $534.9 \pm 34.4$ & $526.7 \pm 37.7$ & $0.003^{*}$ & 0.067 & 0.722 \\
\hline Spherical equivalent (D) & $-3.5 \pm 2.1$ & $-3.1 \pm 1.4$ & $-5.9 \pm 2.3$ & 0.142 & $0.004 *$ & $<.00 I^{*}$ \\
\hline Keratometry value (D) & $44.4 \pm 1.5$ & $44.4 \pm 1.9$ & $45.3 \pm 1.2$ & 0.998 & $0.024 *$ & $0.043 *$ \\
\hline Baseline $\mathrm{CH}$ & $10.1 \pm 1.6$ & $9.7 \pm 1.7$ & $9.1 \pm 1.7$ & $0.039 *$ & $0.03 I^{*}$ & 0.422 \\
\hline Baseline CRF & $10 \pm 1.8$ & $9.4 \pm 1.9$ & $9.2 \pm 1.8$ & $0.012^{*}$ & 0.087 & 0.89 \\
\hline
\end{tabular}

Note: *Indicates statistical significance.

Abbreviations: LASIK, laser-assisted in situ keratomileusis; PRK, photorefractive keratectomy; MMC, mitomycin C; CCT, central corneal thickness; $\mathrm{CH}$, corneal hysteresis; CRF, corneal resistance factor.

comparisons between the three procedures demonstrated statistically significant differences. At 12 months, CRF was similar in all three groups. For all three procedures, CRF remained significantly lower than baseline at 12 months.

$\mathrm{CH}$ was significantly decreased compared to baseline at 3 months and 12 months in eyes that underwent all three procedures (Figure 1B). Again, PRK with MMC showed a significantly greater decrease at 3 months followed by a significant increase from 3 to 12 months, with the final result that all three procedures showed similar $\mathrm{CH}$ at 12 months.

\section{Discussion}

Corneas with ectasia are thought to have biomechanical properties that predispose them to a cone shape. Lower $\mathrm{CH}$ and CRF have been demonstrated in forme fruste keratoconus and keratoconus, ${ }^{10,11}$ and the waveform morphology on ORA of corneas with post-LASIK ectasia differs from non-ectatic corneas. ${ }^{12}$ LASIK is thought to be more likely to cause postoperative corneal ectasia since the treatment occurs deeper in the corneal stroma than PRK. ${ }^{13}$ Accordingly, a greater decrease in corneal biomechanical properties with LASIK than with PRK might be expected. This hypothesis was supported by a retrospective study of LASIK (31 eyes) and PRK without MMC (27 eyes) by Kamiya et al, ${ }^{7}$ which found a greater decrease in corneal biomechanical properties after LASIK. In contrast, we prospectively studied the biomechanical properties of 230 eyes after LASIK and 115 eyes after PRK without MMC (to our knowledge, the largest such study to date) and found similar decreases after both procedures. The lack of a significant difference between
A

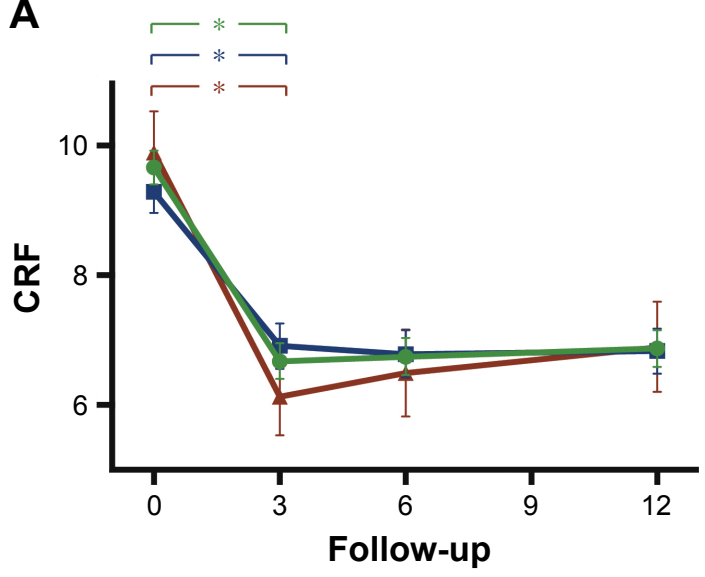

B

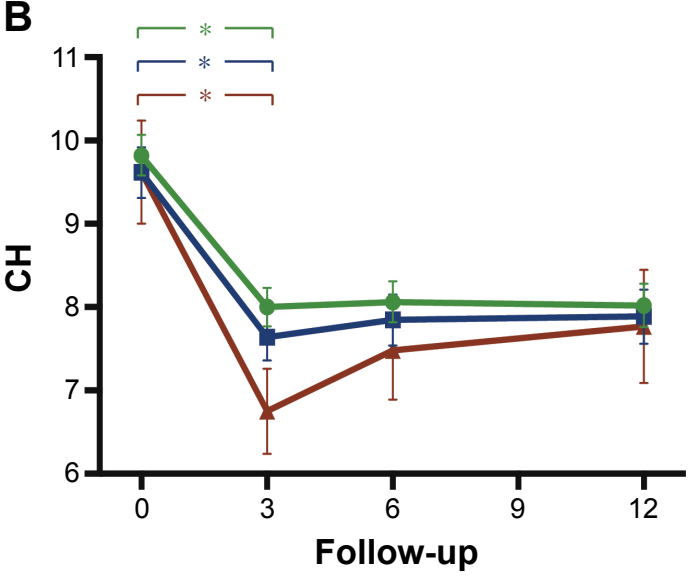

LASIK

PRK

$P R K+M M C$

Figure I Corneal biomechanical properties as measured before and after LASIK, PRK without MMC, and PRK + MMC.

Notes: (A) CRF. (B) CH. *For all three procedures, there was a significant decrease in CRF and $\mathrm{CH}$ at 3 months compared to baseline.

Abbreviations: LASIK, laser-assisted in situ keratomileusis; PRK, photorefractive keratectomy; MMC, mitomycin C; CRF, corneal resistance factor; CH, corneal hysteresis. 
the two procedures likely indicates similar long-term effects on corneal biomechanical properties by LASIK and PRK without MMC.

In contrast to the stability of $\mathrm{CH}$ and CRF measurements after LASIK and PRK without MMC, we found that after PRK with MMC, there was a small decrease in the first 3 months and then a proportionate increase from 3 to 12 months. Thus, at 12 months, $\mathrm{CRF}$ and $\mathrm{CH}$ values were similar for all three procedures. Another group compared PRK with MMC and LASIK in the fellow eye and found lower postoperative $\mathrm{CRF}$ and $\mathrm{CH}$ values at 12 months in the LASIK group. ${ }^{5}$ This study did not report earlier time points, so the changes in $\mathrm{CH}$ and $\mathrm{CRF}$ in the immediate postoperative time period are unknown for their patients. Their randomized study had a larger sample size compared to our study, whereas our study had relatively few patients undergoing PRK with MMC. The difference in our findings may be due to a lack of power in our study.

The main advantage of our study is the large cohort of patients with 3-month, 6-month and 12-month measurements of $\mathrm{CH}$ and CRF after LASIK and PRK with and without MMC. However, a weakness of our study is that the patients were not randomized and the treatment groups differed in baseline refractive error, $\mathrm{CCT}, \mathrm{CRF}$, and $\mathrm{CH}$. To address this, we used a multivariate model to control for differences in baseline characteristics. Although the treatment groups differed preoperatively, the distribution of patients between groups reflects real-life patient characteristics. In routine clinical care, patients who receive PRK differ from those who receive LASIK. Another limitation of the study is that only one measurement was taken at each visit, which could have contributed to larger variability. In addition, although decreased $\mathrm{CH}$ and $\mathrm{CRF}$ values have been found in forme fruste keratoconus, these measurements lack specificity. ${ }^{10}$

Corneal ectasia following refractive surgery is a complication that all surgeons wish to avoid. Many preoperative guidelines to assess ectasia risk have been published. ${ }^{14}$ Corneal measurements by ORA may add to this arsenal and help in identifying patients susceptible to ectasia. Our study specifically examined the effects of LASIK and PRK on $\mathrm{CH}$ and $\mathrm{CRF}$. Significant but similar decreases in corneal biomechanical properties after LASIK, PRK without MMC, and PRK with MMC were noted. This may suggest that the type of procedure is not as important as the native characteristics of the patient's cornea in determining the risk for ectasia. The role of $\mathrm{CH}$ and $\mathrm{CRF}$ measurements in refractive surgery patients is still being elucidated, and further studies will help clarify the relationship of these values with the risk of ectasia.

\section{Acknowledgments}

Christopher M Bair, BS; Brian H Kirk, BS; Jacob Basilius, BS; Randy C Bowen, MD, MS; and Michael G Taggart, $\mathrm{MD}$, contributed significantly to this work. This study was supported by Research to Prevent Blindness (Department of Ophthalmology), National Institutes of Health (NIH) through grant 8UL1TR000105 and Achievement Rewards for College Scientists (BCS and ESH).

\section{Disclosure}

The authors report no conflicts of interest in this work.

\section{References}

1. Luce DA. Determining in vivo biomechanical properties of the cornea with an ocular response analyzer. J Cataract Refract Surg. 2005;31: 156-162.

2. Kotecha A. What biomechanical properties of the cornea are relevant for the clinician? Surv Ophthalmol. 2007;52(suppl 2):109-114.

3. Rosa N, Lanza M, De Bernardo M, Signoriello G, Chiodini P. Relationship between corneal hysteresis and corneal resistance factor with other ocular parameters. Semin Ophthalmol. 2015;30(5-6):335-339.

4. Kamiya K, Hagishima M, Fujimura F, Shimizu K. Factors affecting corneal hysteresis in normal eyes. Graefes Arch Clin Exp Ophthalmol. 2008;246:1491-1494

5. Wallau AD, Campos M. One-year outcomes of a bilateral randomised prospective clinical trial comparing PRK with mitomycin C and LASIK. Br J Ophthalmol. 2009;93:1634-1638.

6. Wang B, Zhang Z, Naidu RK, et al. Comparison of the change in posterior corneal elevation and corneal biomechanical parameters after small incision lenticule extraction and femtosecond laser-assisted LASIK for high myopia correction. Cont Lens Anterior Eye. 2016;39(3): 191-196.

7. Kamiya K, Shimizu K, Ohmoto F. Comparison of the changes in corneal biomechanical properties after photorefractive keratectomy and laser in situ keratomileusis. Cornea. 2009;28(7):765-769.

8. Zare M, Feizi S, Azimzadeh A, Esfandiari H. Effect of photorefractive keratectomy with mitomycin-C on corneal biomechanical features. Curr Eye Res. 2012;37(6):457-462.

9. Hashemi H, Miraftab M, Asgari S. Photorefractive keratectomy results in myopic patients with thin cornea eyes. Oman J Ophthalmol. 2015; $8(1): 24-27$.

10. Fontes BM, Ambrósio R, Jardim D, Velarde GC, Nosé W. Corneal biomechanical metrics and anterior segment parameters in mild keratoconus. Ophthalmology. 2010;117(4):673-679.

11. Johnson RD, Nguyen MT, Lee N, Hamilton DR. Corneal biomechanical properties in normal, forme fruste keratoconus, and manifest keratoconus after statistical correction for potentially confounding factors. Cornea. 2011;30(5):516-523.

12. Kerautret J, Colin J, Touboul D, Roberts C. Biomechanical characteristics of the ectatic cornea. J Cataract Refract Surg. 2008;34:510-513.

13. Randleman JB, Caster AI, Banning CS, Stulting RD. Corneal ectasia after photorefractive keratectomy. J Cataract Refract Surg. 2006;32: 1395-1398.

14. Randleman JB, Russell B, Ward MA, Thompson KP, Stulting RD. Risk factors and prognosis for corneal ectasia after LASIK. Ophthalmology. 2003;110(2):267-275. 
Clinical Ophthalmology

\section{Publish your work in this journal}

Clinical Ophthalmology is an international, peer-reviewed journal covering all subspecialties within ophthalmology. Key topics include: Optometry; Visual science; Pharmacology and drug therapy in eye diseases; Basic Sciences; Primary and Secondary eye care; Patien Safety and Quality of Care Improvements. This journal is indexed on

PubMed Central and CAS, and is the official journal of The Society of Clinical Ophthalmology (SCO). The manuscript management system is completely online and includes a very quick and fair peer-review system, which is all easy to use. Visit http://www.dovepress.com/ testimonials.php to read real quotes from published authors. 